\title{
Subject Specialisation in Primary School: A Theoretical Review and Implications for Policy and Practice in Zambia
}

\author{
Zanzini B. Ndhlovu ${ }^{1,}{ }^{*}$, Bentry Nkhata ${ }^{2}$, Ferdinand M. Chipindi ${ }^{3}$, Bibian Kalinde ${ }^{1}$, Collins Kaluba $^{1}$, Esther Malama $^{1}$, \\ Robinson Mambwe ${ }^{1}$, Katongo Bwalya ${ }^{1}$, Enala S. Lufungulo ${ }^{1} \&$ Hikabwa Chipande $^{1}$ \\ ${ }^{1}$ Department of Primary Education, University of Zambia, Zambia \\ ${ }^{2}$ Department of Mathematics and Science Education, University of Zambia, Zambia \\ ${ }^{3}$ Department of Educational Administration and Policy Studies, University of Zambia, Zambia \\ *Correspondence: Department of Primary Education, University of Zambia, Zambia. E-mail: \\ zanzini.ndhlovu@unza.zm
}

Received: April 26, 2021

Accepted: July 16, $2021 \quad$ Online Published: October 28, 2021

doi: $10.5430 /$ jct.v10n4p13

URL: https://doi.org/10.5430/jct.v10n4p13

\begin{abstract}
The Ministry of General Education (Zambia) introduced subject specialisation at primary school. However, researchers have not yet sufficiently interrogated the concepts and modalities of subject specialisation at the primary school level to build a basis for an informed position and implementation. The paper aimed to review the literature and international practice relevant to subject specialisation at the primary school level. Interpretive techniques were applied while conducting secondary data analyses. The review established that there were different models of specialisation in education. There were also mixed experiences of subject specialisation in teaching and learning at primary school levels from the countries accessed.

Nonetheless, intentional narrowed practice tended to contribute to the competent delivery of service in education. The paper, thus, welcomed differentiated types of specialisation based on school circumstances, learner grade level, staff numbers and teaching and learning facilities. Therefore, the authors proposed a study to explore the assertions and proposals.
\end{abstract}

Keywords: subject specialisation, primary education, learner achievement, continuing professional development, models of subject specialisation

\section{Background to the Study}

Learning achievement of school pupils in Zambia has continued to elude the Ministry of General Education (MoGE). Therefore, in an attempt to improve learner performance, the MoGE circular dated 5th April 2019 addressed to all Provincial Education Officers in Zambia by the Permanent Secretary (Technical Services) of the Zambian Ministry of General Education (MoGE) guided as follows:

[Given] the re-occurrence of poor learning outcomes over the years at the Primary Sub-Sector, especially in numeracy and literacy and the need for a strong foundation for our learners, the Ministry has decided to introduce a system of specialisation at this level (GRZ, 2019, p. 1).

Documentation and systematic assessment of learning achievement at the national level in Zambia can be traced to 1998 when the Ministry of Education (MoE) assessed learning achievement nationally and examined how this would be changing over time. This assessment was conducted in Grade 5 (in a seven-year primary school cycle), focusing on English and numeracy. In some provinces, the assessment was in Zambian Languages too. Arising from this national assessment exercise was the conclusion that:

In terms of the learning achievement of school pupils, Zambia appears to be a nation at risk. The critical state of learning achievement which the National Assessment has documented is not confined to Grade 5. The MLA (Monitoring Learning Achievement) and SACMEQ (Southern Africa Consortium for Monitoring Educational Quality) investigations indicate that low levels of learning achievement are equally 
characteristic of Grades 4 and 6 . The overall conclusion seems inevitable: levels of learning achievement are low right across the country, in all grades and all curriculum areas. Very little learning occurs in Zambia's schools (Kelly \& Kanyika, 2000, p. 8).

In the 2016 National Assessment Report, learning achievement at Grade 5 had not changed from the first edition of 1999 except for the consolation that there had been no decline despite the 'massive enrolment' at that level (Examinations Council of Zambia, 2016). Several factors impinge learning achievement. They include home background, school-home background factors and processes, school background factors and processes, teacher factors, school headteacher factors, and learner factors (Ministry of Education Science Vocational Training \& Early Education, 2013). According to some scholars, the teacher factors are the most significant (Darling-Hammond, 2000 and Hammond, 2014). School home background factors and processes, especially as embodied in the curriculum, are of great significance too. Regarding the teacher factor, several large scale interventions have been implemented to enhance teacher capacity.

\section{Measures to Enhance Teacher Capacity}

The persistent low achievement levels defy the relatively high level of investment in education. "It is striking that student learning outcomes remained stagnant over time, regardless of student or school characteristics" (Ministry of General Education, 2017, p.2). Over the past three decades, investment in education has involved several large-scale interventions in enhancing teacher capacity. One of the most extensive interventions was Action to Improve English, Mathematics and Science (AIEMS). The AIEMS project, jointly funded by the Zambian and British governments, began in 1994 and ended in 2000. The project's main aim was to improve the quality of teaching Science, English, and Mathematics by providing a decentralised, sustainable system of in-service education through a nationwide network of resource centres. AIEMS culminated into the School Programme of In-service for the Term (SPRINT). SPRINT was a highly systematised framework for Continuing Professional Development (CPD) which focused on small teachers' groups meeting regularly within their school and supported in their efforts by the resource centres and in-service providers at various levels of the education system. Through the Teacher Group Meetings, teachers talked with one another and supervisors to solve professional problems and support each other through discussion, modelling, and coaching. Teachers were encouraged to be responsible for their professional development and growth to become more reflective and practical classroom practitioners.

The Basic Education Sub-Sector Investment Programme (BESSIP) was yet another large scale programme supported by several cooperating partners. The programme ran from 1998 to 2003 . It had the objectives of increasing enrolments, improving internal efficiency in the Ministry of Education and improving learning outcomes. The programme developed an accelerated pre-service teacher education programme to meet expanding teacher requirements. Further, it embarked on upgrading teachers' pedagogical skills and professional qualifications through strengthening in-service programmes at Teacher Resource Centres and Teacher Training Colleges (Hebert. et al., 2002). The programme arose against the backdrop of declining enrolment, high dropout, retention rates and deficient student academic achievement, especially among the country's poorest. Nevertheless, the programme registered some successes in enrolment and the other variables, although there was a negligible increase in learners' learning achievement. According to the BESSIP evaluation report, the programme delivered many aspects but improved learning outcomes (BESSIP Evaluation Report, 2007).

The Professional Support Structure for Primary Education (PSSPE) was a component under BESSIP which ran from 2000 to 2007. This initiative aimed to enhance the capacities and competencies of teachers to help improve learning achievement in primary schools. Thus the focus of the programme was on primary school teachers. The strategy was to raise the status of primary school teachers by, among the means, raising primary school teachers' qualifications from certificate to diploma, as was the case with their secondary school counterparts. PSSPE also advocated for degree programmes in primary education to pave the way for an academic career path for primary school teachers. This meant that primary school teachers could obtain qualifications up to the highest level possible in primary education and thus reverse the 'brain-drain' from primary to secondary education.

In the continued efforts to address the quality of learning, the Ministry of Education (MoGE) in 2013 revised the curriculum at all levels; Early Childhood Education (ECE), Primary Education, Secondary Education and Teacher Education (MOESTVEE, 2013). This was motivated by learners' continued poor performance, as reflected in the National Assessment Systems (ECZ, 2018) and SAQMEC (2018). In addition, the Ministry observed that there was a lack of alignment between the school curricula and Teacher Education curricula. More importantly, the curriculum sought to conform to the adopted outcomes-based learning to direct educational efforts towards what learners can 
demonstrate in terms of knowledge, skills, and values upon completing a course of study in line with expected proficiency levels.

The Zambian government also revised the teacher education curriculum. The revised curriculum, which was still in its implementation phase, emphasised adequate knowledge in all areas (in an integrated form), focusing on practice and outcomes. The expectation was that teachers would be mediators and applicators of knowledge at ECE, Primary or Secondary School with curricula and comprehensive learner understanding. The 2013 curriculum reforms emphasised outcomes and the quality of teachers. However, what was missing was the type of teacher - a generalist or a specialist? The Teacher Education curricula for Primary Education at the time of writing this paper in 2021 was modelled for generalist teaching. The system expected the teacher to teach all subjects to one group of learners each year.

\section{Statement of the Problem}

The Ministry of General Education (MoGE) in Zambia was alive to multiple factors influencing learning achievement as being:

a) qualified teachers that have a deep mastery of both the subject content and pedagogy that supports deep learner-centred learning,

b) healthy quality learners, who have had stimulating early childhood experiences and have supportive home environments,

c) a quality learning environment that has good facilities and is safe, peaceful and inclusive,

d) availability of adequate and appropriate teaching and learning materials,

e) a curriculum that has clearly defined grade-level appropriate learning outcomes and emphasises the acquisition of knowledge, skills and values,

f) a supportive administrative and leadership structure at all operational levels that ensures effective utilisation of human, financial and time resources. (MoGE, 2018).

Of all the factors influencing learning achievement, Darling-Hammond $(2000,2014)$ isolates the teacher as the most influential factor impacting children's quality of learning. Because of this, the present paper shall focus in considerable measure on the teacher. By policy, training and practice, teachers at the primary school level in Zambia were, until 2019, generalists who taught all the subjects. Therefore, it is reasonable to expect that not every teacher will have the desired competence, knowledge, skills, and attitudes to teach every subject effectively. The MoGE circular of $5^{\text {th }}$ April 2019, mentioned earlier, indicating abandonment of this generalist approach to teaching at the primary school level, was not preceded by an empirical study to unravel the threats and opportunities inherent in such a move. Researchers have, as yet, not sufficiently interrogated the concepts and modalities of subject specialisation at the primary school level to build a basis for an informed policy position and implementation.

\section{Purpose of the Study}

This study aims to review relevant literature and international practice relevant to subject specialisation at the primary school level to inform policy and practice in Zambia.

\section{Specific Objectives}

The following objectives guided the review,

1. To review the literature relevant to specialisation in education

2. To examine international practice regarding subject specialisation at the primary school level

3. To present implications regarding subject specialisation at the primary school level in Zambia.

\section{Methodology}

This paper's content is based on information collected through reviewing the available literature relevant to teacher education developments in Zambia and subject specialisation at the primary education level within Zambia, Africa, 
and beyond. The review mainly involved official government published reports, statistics on teacher education, and journal articles from the library and internet.

Interpretive techniques (coding and recursive abstraction) were applied while conducting secondary data analyses. Validity was addressed as a central challenge to ensure the credibility of the review. We also employed reference check, conformability and balancing as ways of establishing validity. The literature review also covered global publications on subject specialisation experiences in different education contexts within Africa and beyond and on subject specialisation models.

\section{Limitations}

Possible limitations of the methodology and techniques presented above are that information collected through this approach might omit critical details and ongoing dialogues in the arena. The approach may also result in underreporting of specific issues. It is also important to acknowledge that the accuracy and completeness of data may vary from one country to another. Consequently, the implications and recommendations should be generalised sparingly within the context of the information presented and based on the documents, reports, and publications included in this review.

\section{Findings}

\subsection{Models of Specialisation in Education}

Before delving deep into our review, it is pertinent to operationalise the fundamental construct in our study, specialisation. The concept denotes people repeatedly doing a single task to improve and raise their production efficiency. It entails breaking each job into smaller tasks that are manageable. In this regard, specialisation is assumed to improve quality and efficiency in production. In the educational realm, there are several models of specialisation utilised. In the pages that follow, we highlight some of these models.

Specialisation in teacher education could be described in different ways. It could be in the context of teachers being allowed to focus on one or two subjects assuming that this gives teachers affirm subject matter grounding in a single discipline or two. In this case, teacher subject specialisation denotes an in-depth mastery and expertise in a particular subject area. It also means 'certification bodies' demanding higher standards of subject matter preparation much more than any other skills before achieving a license to teach (Howard, 1969; \& Roy, 2016). In addition, it could also involve intentional narrowing of practice, contributing to competent service delivery in education (Kasher, 2005). For example, subjects are grouped into expressive arts, languages, sciences or technology and based on such groupings with teachers assigned to teach the grouped subjects or areas depending on their expertise. Other possible subject groupings or narrowing of practice could focus on core curriculum subjects and support subjects. A specialisation that involves allocation to teaching core subjects is also referred to as the teacher instructional model in which teachers provide instructional support in subjects allocated to them (Scwartz \& Gess-Newsome, 2008). Embedded in specialisation along core subject areas is the idea of 'relief time' teachers referred to an intervention specialist or subject coaches who work alongside the teachers of core areas (McGatha \& Rigelman, 2015). In most instances, literacy, numeracy, and science are considered core areas in curriculum organisation, which specialists must teach.

Other conceptualisations suggest that the concept could refer to an area or skill, breaking down the subject matter by looking at the teaching and learning process. For example, teachers have different competencies or areas of strength or agility in teaching a subject. According to Howard (1969), based on her evolution of the teaching and learning process in schools, she highlighted 'team teaching' as an acceptable practice that called for a different type of specialisation. In this scenario, other teachers possessing varied specialist skills in the actual teaching phase come on board. According to Howard, teachers' identified pedagogical strengths can be utilised as specialities in different subject areas. Another form of specialisation is the collaborative specialist model, which also uses the term 'team teaching' focuses on a subject-specific department. It aims to provide instruction coordinated in a subject-specific department to multiple classes (Scwartz \& Gess-Newsome, 2008). According to Nelson \& Landel (2007), a collaborative specialist model is broader than team teaching in its teacher collaboration and emphasises teacher performance as a basis for sharing content in a specific area and broadly includes how content is shared and assessed. Having defined the term, we now transition to analyse empirical and conceptual studies that focus on the specialisation at the primary school level in different parts of the world. 


\subsection{Studies of Subject Specialisation and Generalist Teaching}

Fryer (2018) conducted a randomised field experiment in traditional public elementary schools in Houston, Texas, the USA. The study was designed to test the potential productivity benefits of teacher specialisation. He found that although teacher specialisation at primary school increased the "quality of human capital available to teach students through sorting (p. 654)" it might have led to inefficient pedagogical choices. Fryer also found that teacher specialisation decreased student attendance and increased student behaviour problems possibly arising from a weakened teacher spotlight on child behaviour because of the multiplicity of teachers.

Similarly, Bastian, Fortner and Caton (2019) investigated the theoretical promise that subject-area specialisation represented a low-cost approach for schools to, among other issues, increase student achievement arising from assigning more students to the classrooms of more effective teachers. The study found that the incidence of specialisation was rare in early elementary (primary school). Only 5 to $7 \%$ of teachers specialised. The study also found that specialisation was more prevalent in upper primary grades. In addition, the study revealed that schools assigned relatively more effective teachers to specialise. This assignment suggested that specialised subject-area teaching need not be premised on specialised subject-area training. Finally, the study found that teachers were less effective in mathematics and reading after becoming subject-area specialists but were more effective in science and social studies. One explanation suggested for this was that subject-area specialisation led to fewer interactions between teachers and students to allow for providing individualised attention.

De Vries (2013) undertook a qualitative inquiry into music teaching by so-called generalist teachers. The study employed narrative inquiry methods centred on the biographical insights provided by generalist teachers who had shown an affinity towards music teaching. The study yielded various motivations for the failure or reluctance of this category of teachers to teach music in the primary classroom. Although peripheral to this paper, De Vries' study is worthy of attention because it highlights inevitable tensions that might occur in the spaces where subject specialisation occurs alongside generalist teaching approaches. In this case, the teaching of music attracts divergent views from both generalist and specialists' teachers. The generalist teachers appear to have low self-efficacy in music teaching; thus, they declare themselves unable to teach the subject. Instead, they prefer that a specialist teacher is more suited for the particularities of music as a subject.

On the other hand, the rich ethnographic posture adopted by the researcher uncovers substantial evidence that credence to the suggestion that the teaching of specific issues by the generalist could at best be achieved by enlisting the aid of trained specialists, who in addition to the training, have a musical background. This study ultimately highlights the fact that the ground between specialisation and generalist teaching is not always navigable. Some nuances are always present that would influence the adoption of one approach to the exclusion of the other.

A study on physical education in Canada revealed generalist teachers' inadequacies, stressing a lack of knowledge and skills to provide learners with developmentally appropriate, varied and sequenced content. Some generalist teachers were described as remote-control teachers who "drop students off and return at the end of the lesson, leaving them to do 'their own thing" (Decorby et al., 2005: 209). On the other hand, specialist physical education teachers have time to prepare lessons across grades, become informed advocates for improved resources for the subject, provide leadership in procuring equipment, and coordinate extracurricular sports activities in the whole School (Decorby et al., 2005: 209).

In North America, the Elementary Teachers' Federation of Ontario (ETFO), Canada, commissioned a study to examine specialist teachers' existing evidence and the relationship with student achievement at the elementary school level. The research done by Pollock \& Mindzak (2015) was systematic, utilising several electronic databases and keywords (English Language publications and documents) that focused on specialist teachers at the elementary school level. In addition, they sought to establish what literature said about the relationship between specialist teachers and student achievement, among other questions. The research project reviewed a total of 197 documents using a phased approach. The activity also involved coding and categorising the data into significant themes. The categorisation subsequently involved evaluating sources concerning relevance, quality, reliability, methodology and theoretical framework.

Their review established that student achievement could not be measured only in the narrow perspective of grades or test scores. Instead, we could measure it in the many intrinsic and extrinsic rewards and benefits for students on a short and long term basis; learner achievement should incorporate; the emotional, physical, cognitive, affective, personal and social development of students. In addition, some studies in the reviewed literature showed that teachers with higher levels of self-efficacy in a subject and more content-area knowledge could employ more robust pedagogical strategies. However, the exact relationship between such teacher characteristics and student achievement 
remained unclear. The review thus concluded that literature surrounding specialist teachers and student achievement indicated that specialist teachers could instruct students in a high-quality and effective manner; however, the evidence regarding the impact on student achievement was ambiguous and inconclusive.

\subsection{Experiences with Subject Specialisation in Selected Countries}

Diverse manifestations of specialisation are evident in different jurisdictions around the world. Prasad (2011) did a study in Fiji, which advanced the proposition that the primary school system needed to change from a general teacher to a subject specialist to enhance student achievement and teacher specialisation. The study proposed subject specialisation in primary teacher training institutions rather than a generalist education model at primary school. The study indicated that it was essential that teachers specialise in at least two subjects at teacher training institutions. However, the study revealed that the significant challenges related to subject specialisation at primary schools would relate to the degree of specialisation needed at teacher training institutions and school expectations.

In Australia, there was some variance in how researchers encountered the phenomena. For instance, the Teacher Education Ministerial Advisory Group (TEMAG) investigated the efficacy of subject specialisation in selected country regions. Their study uncovered a decline in the engagement and participation of students in mathematics and science after the introduction of subject specialisation. It also noted a lack of confidence by the teachers in these areas. As a result, TEMAG recommended that teacher education in higher education institutions provide and equip all primary and pre-service teachers with specialised training in at least one subject. It also recommended prioritising science, mathematics or a language to prepare teachers to teach in each of the learning areas of the primary school curriculum. This was critical as it ensured skills and knowledge in mathematics and science. However, a qualitative study by McMaster et al. (2018) revealed that the nature of 'specialist' roles in a school depended heavily on the funding arrangements and the levels of existing expertise. In Australian primary schools, formal numeracy leadership positions were only possible through surplus funding to the usual funding models. The traits that principals wanted from new specialists were; knowledge for teaching mathematics, personal attributes, and relationships with others with leadership qualities anticipated across all three. McMaster et al. found that even when schools had funds to employ an additional teacher as 'mathematics specialists', their role would be to provide professional development and support for other teachers, not teaching mathematics for them.

Jeanneret and Ballenger (2013) investigated the impact of high-quality teacher training on Music Education in Victorian Primary Schools. The study involved two teacher training pathways; primary generalists and secondary specialists. They extended both pathways by opening up a primary Teacher training course to secondary school music specialists to build their capacity to teach in primary schools while opening 12 hours for primary teachers to practice music in the arts to artistry studio classrooms. It was found that although this extended intervention was optional, two-third of the secondary specialist teachers enrolled. In addition, generalists found collaborative teaching with specialist music secondary teachers beneficial in building their repertoire of skills and activities for holistic primary music education.

In contrast, specialist Music teachers had a competitive edge and stood a better chance of employment in primary or secondary schools. The Teacher Educators found the extended courses and opportunity for generalists, specialists, and artists to collaborate on their pedagogical practices and were later sent to primary school to collaboratively teach music with primary generalist teachers. This study demonstrated that teachers should enrich their programs with extra curriculum to practice, especially in practice-oriented subjects. This could enrich the teacher's capacity to handle practical subjects and inculcate the attitudes of collaborative teaching in their future professional practice.

A similar picture emerged from Scandinavia. The Danish' folkeskole (a one-year pre-school class, a nine-year primary and lower secondary school and a one-year 10th form) employs a unique "class teacher" system. One teacher is responsible for a class for nine years (Danish Ministry of Education, 2007). Thus, pupils remain together in the same class for all nine years. The class-teacher supervises all pupils' academic, social, and personal development and links the children's homes and the school.

Regarding teacher training, programmes cover the whole period of compulsory schooling with a minimal specialisation of subjects, clearly distinguishing primary and lower secondary school teachers from other teachers' categories (Winther-Jensen, 2001). The training takes approximately four years, with a degree as the minimum qualification for primary school teaching. The Ministry of Education is responsible for setting achievement targets for each subject taught in the folkeskole; however, local authorities and schools can decide how to reach these.

The general agreement is that education should be about general subject-specific skills, such as reading/writing/arithmetic; personal qualifications such as creativity, cooperation, independence and intellectual 
skills; and specific competencies related to working life (Danish Ministry of Education, 2007). Furthermore, as the schools must emphasise each pupil's personal and social development, an intimate collaboration between the school and the pupil's home is considered vital. Pupils and parents or guardians must accordingly receive information about the child's academic and social performance at school at least twice a year.

In the Southern Africa region, similar patterns were evident. Botswana is one of the countries in Africa that has implemented specialisation in primary schools. A study by Makhila (2008) found that despite practising subject specialisation in primary schools, some teachers were frustrated by the model as it was not necessarily specialisation but subject sharing. The study also revealed that specialisation in infant classes proved difficult because pupils were very young to differentiate the subject discipline and the swapping of classes by teachers. The study, however, welcomed specialisation at the upper primary. The researcher concluded that subject specialisation in primary teaching in Botswana was in its infancy hence the challenges faced. The teachers' perception is that it is impossible to implement it unless resources are invested in the specialisation. Other challenges that impeded specialisation in this jurisdiction were lack of teaching and learning materials, inadequate classrooms, teachers and supervisors' negligence, and insufficient teacher and student support systems.

Research studies conducted in Zimbabwe yield similar insights. For instance, a study by Majoni (2016) revealed that specialisation had several advantages. Firstly, the pupils enhanced their performance and pass rates. Secondly, broader subject coverage gave the teacher adequate time to research and understand the syllabus. Thirdly, having various teachers brought some variety in the classroom, making learning exciting and, in the process, improving learning. However, the study also uncovered some challenges faced in implementing subject specialisation: inadequate infrastructure and resources; the congested timetable; the negative attitudes of pupils towards individual teachers; difficulty to monitor truant pupils; no help to slow learner; high teacher pupils' ratio. However, the study concluded that subject specialisation was relevant in primary school teaching and learning (Majoni, 2016). In addition, the study highlighted some advantages of specialisation. They included: enhanced pupils performance, pass rate, broader subject coverage, teachers having time to research and adequate coverage of syllabus; various teachers bring variety in the classroom making learning exciting, thereby improving learning (Majoni, 2016).

Similarly, Samkange (2015)'s study (also in Zimbabwe) assessed pupils' attitudes and perceptions, teachers and parents towards subject specialisation at primary school. Samkange found mixed views on the role of subject specialisation at the primary level. The study findings were not conclusive on how specialisation contributed to improved quality of education in the two schools because different respondents viewed subject specialisation differently. Some noted that it positively impacted teacher performance, motivation, and pupil performance, as teachers had ample time to interpret the syllabus. At the same time, others noted that subject specialisation had impacted negatively on teacher-pupil relationships. The study further showed that subject specialisation at primary school compromised discipline among pupils, as subject specialists did not play the pastoral role of generalists. In some cases, the teacher did not possess sufficient knowledge of the subject they were supposed to teach (Samkange, 2015). The two studies in Zimbabwe suggest that if specialisation is implemented effectively, it can enhance teaching and learning and improve education quality.

In Zambia, a survey conducted amongst primary school teachers in Lusaka district established that most teachers in Lusaka favoured subject specialisation. Moono et al. (2019) 's study revealed that the reasons given for this preference were that it was perceived to enhance the quality of teaching and learning because teaching one or two selected subjects would give them ample time to prepare lessons. Further, the study observed that pupils improved academic performance in schools practising 'subject' specialisation. However, the study also noted some challenges with specialisation. Moono et al. (2019) observed that the authorities tended to allocate teachers to subjects they were not competent in some cases, potentially dampening their mood and morale for teaching. In addition, the lack of adequate subject knowledge in some subjects was the major weakness of the generalist teacher. The study's recommendations noted that school managers should allow teachers to choose the subjects they wanted to specialise. Also, that school managers should promote continuous professional development to enhance quality teaching.

Our review shows that subject specialisation or the lack of it can mean a wide variety of practices. It could mean a teacher focusing on a single subject or a group of subjects; it could mean specialising in teaching a specific grade, e.g. Grade 1, and teaching a phase of the primary school cycle, e.g. lower or upper primary. Fryer noted, for example, that 'of the 34 OECD countries, five begin specialising teachers during or after Grade 3. Those who do not use specialised teachers take generalist teaching a stage further where the average teacher in these countries stays with the same group of primary school children for at least three years (Fryer Jr., 2018). Generalist teaching for a sustained period in early grades is premised on prioritising teacher-learner relationship at that stage of schooling over 
teacher subject knowledge masterly (Bastian, Fortner, \& Caton, 2019).

Nevertheless, other studies uncovered the adverse effects of subject specialisation on teacher-pupil relationships. At times, it compromised discipline among pupils, as subject specialists did not play the pastoral role played by generalists. In some cases, there was a lack of knowledge of the subject specialist by the teacher's subject (Samkange, 2015). Further, implementation of subject specialisation lacked adequate infrastructure and resources; congested timetable; pupils' negative attitude towards individual teachers; difficulty to monitor truant pupils; no help to slow learner; high teacher pupils ratio (Majoni, 2016). Nevertheless, the evidence suggested that subject specialisation was relevant in primary school teaching and learning and proposed an appropriate model to be designed to ensure its effectiveness. Makhila (2008) also indicated that teachers had reservations on specialisation implementation unless the government invested in the attendant resources. Other challenges noted that impede specialisations were lack of teaching and learning materials, inadequate classrooms, negligence by both the teachers and supervisors, and insufficient teacher and student support systems as significant challenges. In Fiji (Prasad, 2011), the significant difficulties were the specialisation needed at teacher training institutions and school expectations.

Our review of the above studies presents mixed experiences of 'subject' specialisation in teaching and learning at the primary school level; positive and negative experiences exist. The positive experiences referred to impact on teacher performance, teacher motivation and pupil performance. They also resulted in ample time for the teacher to interpret the syllabus. In the section that follows, we synthesise the literature to isolate the fundamental messaging around specialisation.

\section{Discussion}

\subsection{Specialisation in Primary Education}

The specialisation models presented above refer to the narrowing of practice in some way; to specific content in a subject, subject or subject, or pedagogic skills in the teaching and learning process or collaborative specialist coordinated in a subject-specific department. The models could apply to teachers already in service (practising) or yet to be trained. Nonetheless, the models do not specify education level - early childhood, primary, secondary or tertiary education. The focus of the review, however, was primary education. These models have their strengths and weaknesses, depending on the context of implementation.

In subject specialisation, where teachers focus on one or two subjects, teachers pass through a dedicated education programme in a tertiary institution. Therefore, teachers have an in-depth mastery and expertise in a particular subject area and are likely to be more competent in the subjects they teach. Ball and Bass (2000) noted that understanding and knowing subject matter knowledge was imperative if teachers create suitable learning opportunities. The narrowed focus might also free time for teachers to concentrate on their subjects. The subject specialisation system allows learners to be taught by several teachers depending on the number of subjects on offer (Thomas et al., 2020; Ndhlovu, 2017; Chipindi \& Chipindi, 2016; Moono et al., 2019; Ndawi, 2002; Honnessey, 2000; Makhila, 2008).

This model's weaknesses are that it isolates the teachers and subjects, leading to subject compartmentalisation, which promotes curriculum fragmentation. Since primary school involves relatively younger learners, changing teachers for different subjects harms socialisation and emotional progress (Ndawi, 2002). There is also a detached teacher-pupil relationship owing to learners having many teachers. Thus, specialists might have been less able to meet particular student needs and less able to integrate and reinforce academic content throughout the day. As Cockcroft (1982) said concerning effective teaching of mathematics, "the many different topics which exist within mathematics ... should be presented and developed in such a way that they are seen to be interrelated (p. 73)". The opportunity to interconnect learning across subjects is less robust under subject area specialisation than generalist teaching. Grouping the subjects into core subjects and other subjects offers a means of improving staff utilisation to promote shared planning, shared teaching, and evaluation amongst the teachers involved. However, the weakness is that subjects' demarcation as core and peripheral may relegate subjects into significant and less significant, thereby raising questions on the epistemological beliefs attached to specific subjects in the curriculum. Furthermore, according to Samkange (2015), this is likely to breed organisational tension in a school.

The specialisation at the primary school level, especially in upper grades, involves teaching one or two subjects (Subject specialisation). However, it is not clear that subject knowledge and higher quality teaching are more likely to come from subject specialists than from other types of specialisation. Thornton (1998) argues that there is a need to establish where the differences lie, the underlying causes of the 'good teaching' cited, and relate it to the level and source(s) of teacher knowledge before claims for specialist teaching can be established. Hard evidence is needed, not 
assumptions or assertions. Thornton quoted official pronouncements about specialist teaching's superiority (OFSTED, 1997, paragraphs 3 and 18) but pointed out that no evidence was produced to support the assertions. What mattered was the quality of teaching as a whole (Thornton, 1998).

Finally, team teaching (collaborative specialist model), a form of specialisation (Howard, 1969), focused on a pedagogical skill, has the strength of focusing on the actual practice of teaching and learning. It could take on board the whole range of teaching and learning; the content -concept development, diagnosis of learning needs, simulations and others. It also has the advantage of pulling together different teachers' strengths into the process of teaching while at the same time building capacity into the participants as they interact. According to Howard (1969), pedagogical skill specialisation fits into the evolving school environment. This system's weaknesses are that coordination across subjects might be complex, and identifying the specialities may also be problematic. Whatever its manifestations in different parts of the world, specialisation can present unique challenges and opportunities in different contexts. A specific locale, such as Zambia, will have its unique possibilities with subject specialisation. It is to these that we now turn.

\subsection{Implications for Specialisation at Primary School Level in Zambia}

It is clear that the persistently poor learning outcomes triggered the policy decision to introduce specialisation in Zambia. The fundamental motivation of subject specialisation is to ensure efficiency, effectiveness and improved performance. There is little doubt in the reviewed literature that some form of specialisation could contribute to the quality and efficient provision of learning. Children's successful learning in a subject is linked to teachers' knowledge in the area. Making content accessible to learners requires teachers to understand the subject matter and appreciate how students learn this subject matter (Bransford, Darling-Hammond, \& LePage, 2005; Shulman, 2005a). However, the landscape of influences and opportunities for a child's development and learning involves many interrelated approaches, curricula arrangements, settings, services and stakeholders. Consequently, there should be a careful balancing of acts involving the curriculum, teachers, resource provision (appropriate environment) and learners' well-being. The crust of the matter is how primary education can facilitate learners' intellectual, social and personal development.

The significant point here is that being an effective teacher is not solely associated with individuals specialising in specific curriculum areas. Being an effective teacher is a quality that can be built in every teacher. Therefore, there is a need for a supportive policy framework and teacher workloads (McDiarmid \& Clevenger-Bright, 2008). We recognise that Zambia has these teacher communities. In the School Programme of In-Service for the Term (SPRINT) system, they are called Teacher Groups. Meaningful and faithful use of Teacher Group Meetings, mostly faithful conduction of Lesson Study cycles, is meant to cultivate accomplished teachers as envisaged by Shulman and Shulman. Thus, we recommend specialisation based on teachers' existing strengths. This, coupled with existing teachers' support systems in schools, such as SPRINT, Lesson Study, and other CPD initiatives, should invigorate teachers' potential for learners' benefit. Therefore, we propose differentiated specialisation based on school circumstances, learner grade level, staff numbers, and teaching and learning facilities. In particular, we advocate specialisation based on teacher skills. This is especially for early grades where the focus is mainly on developing, identifying and promoting learners' eagerness to learn, interests, talents and social competencies apart from imparting knowledge, skills and attitudes that serve to acquire literacy, numeracy, social sciences and use of ICTs.

As learners progress, other specialisation forms such as grouped subjects or collaborative specialist teaching could be considered alongside specialisation based on teacher skills. For example, collaborative specialist teaching and narrowed focus on core subjects could be regarded for upper primary grades. This proposal is anchored on the strength of a CPD system existing in the schools. Such a support system is vital for teachers in their identified areas of strength. The literature that we have reviewed appears to converge on the role of subject specialisation improves teachers' performance and hence learner achievement in schools.

\section{Conclusion}

Our engagement with the literature has established that subject specialisation can increase the quality of human capital; this could be in a specific subject area, pedagogical area or skill. If properly harnessed and integrated among teachers, it could bring about a rich repertoire of skills and resources for the student's good. In addition, the increase in content area knowledge ensures a higher level of self-efficacy by a teacher. However, the relationship between these teacher characteristics with student or learner achievement is unclear. What was also evident in the review is that teacher preparation for primary schools, whether generalists or specialists, was muddled with nuances that could 
sway adopted decisions either way. Our review points to harnessing the best practices in CPD arrangements existing rather than isolating or assigning individual teachers to a class based on an area of interest or preference. Subject area specialisation in Zambia requires a comprehensive empirical study. The preceding discussion has been based on desk review. What is needed now is a comprehensive empirical study to explore these assertions and proposals that would best settle the claims for the Zambian context. In the interim, the specialisation experiment could be done at the upper primary school level only.

\section{References}

Ardzejewska, K. (2010). Delivering the primary curriculum: The use of subject specialist and generalist teachers in NWS. Issues in Educational Research, 20(3), 203-219.

BESSIP Evaluation Report, (2007). Basic Education Sub-Sector Investment Programme (BESSIP). IEG ICR Review Independent Evaluation Group. Report number ICRR 12600.

Bransford, J., Darling-Hammond, L., \& LePage, P. (2005). Introduction. In L. Darling-Hammond \& J. Bransford (Eds.), Preparing teachers for a changing world: What teachers should learn and be able to do (First edition, pp. 1-39). San Francisco: Jossey-Bass.

Chipindi, F. M., \& Chipindi, S. J. (2016). Trade-off issues in teacher education at the university of Zambia: Growing student numbers and the quality of teacher education processes. International Journal of Teaching and Learning in Africa, 3(1), 82-86.

Danish Ministry of Education (2007). Act on the folkeskole. Copenhagen: Undervisningsministeriet.

Darling-Hammond, L. (2000). How teacher education matters. Journal of Teacher Education, 51(3), 166-173. https://doi.org/10.1177/0022487100051003002.

Darling-Hammond, L. (2014). Strengthening teacher preparation: the holy grail of teacher education. Peabody Journal of Education, 89, 547 -561. https://doi.org/10.1080/0161956X.2014.93900.

Darling-Hammond, L., \& Bransford, J. (2005). Preparing teachers for a changing world: What teachers should learn and be able to do. San Francisco: Jossey-Bass.

De Vries, P. (2013). Generalist teachers' self-efficacy in primary school music teaching. Music Education Research, 15(4), 375-391. https://doi.org/10.1080/14613803.2013.829427

Decorby, K., Halas, J., Dixon, S., Wintrip L., \& Janzen H. (2005). Classroom teachers and the challenge of delivering quality physical education. The Journal of Educational Research, 98(4), 208-221. https://doi.org/10.3200/JOER.98.4.208-221

Examinations Council of Zambia (2012). Learning achievement at the primary school level: Zambia's national assessment survey report - 2012. Lusaka: Ministry of Education, Science, Vocational Training and Early Education.

Hebert A. P., Lungwangwa G., Nance W. B., \& Saasa S. O. (2002). Review and Analysis of Zambia's Education Sector. Washington D.C.: L.T. Associates, Inc.

Honnessey, S. (2000). Overcoming the red feeling. The development of confidence to teach music in primary schools amongst student teachers. British Journal of Music Education, 20(3), 204.

Howard, E. (1969). A look at specialisation. Educational Leadership, 547-550. Retrieved from https://education.stateuniversity.com/pages/371/Denmark- primary-preprimary- education.html

Jorgensen, R. (2016). Middle leadership: A key role in numeracy reform. Australian Primary Mathematics Classroom, 21(3), 32-37.

Kasher A. (2005). Professional ethics and collective professional autonomy: A conceptual analysis. Ethical Perspectives: Journal of the European Ethics Network, 11, 67-98. https://doi.org/10.2143/EP.12.1.583363

Kelly, M. J., \& Kanyika, J. (2000). Learning achievement at the middle basic school level: Final report on Zambia's national assessment project 1999. Lusaka: Ministry of Education.

Levy, A. J., Jia, Y., Marco-Bujosa, L., Gess-Newsome, J., \& Pasquale, M. (2016). Science specialists or classroom teachers: Who should teach elementary science? Science Educator, 25(1), 10-21.

Majoni, C. (2016). Challenges in implementing subject specialisation by primary teachers in Zimbabwe. 
IJRDO-Journal of Educational Research, 1(2), 2-11.

Makhila A. S. (2008). Teachers' perceptions towards subject specialisation by primary school teachers: The case of implementing schools in North East regional education primary schools (Unpublished Master's thesis). the University of Botswana.

McDiarmid, G. W., \& Clevenger-Bright, M. (2008). Rethinking teacher capacity. In M. Cochran-Smith, S. Feiman-Nemser, D. J. McIntyre, \& K. E. Demers, K. E. (Eds.), Handbook of research on teacher education: enduring questions in changing contexts (Third edition, pp. 134-156). New York: Routledge.

McGatha, M. B., \& Rigelman, N. R, (Eds.) (In Press). Elementary mathematics specialists. association of mathematics teacher educator (AMTE).

McMaster, J. H., Bobis, J. Way, J., \& Beswick, K. (2018). Principals' perceptions and expectations of primary teachers with a specialisation in mathematics (Proceedings of the 41st annual conference of the Mathematics Education Research Group of Australasia) pp. 551-558. Auckland: MERGA.

Ministry of Education, Science, Vocational Training and Early Education (2013). Zambia National Numeracy Framework. Lusaka: CDC.

Ministry of Education, Science, Vocational Training and Early Education (2013). Zambia Education Curriculum Framework 2013. Lusaka: Government Printers

Ministry of General Education. (2017). Project Implementation Manual: Zambia Education Enhancement Project. Lusaka: Author.

MOGE, (2019). Specialisation of teaching at the primary subsector. Lusaka: Circular to Provincial Education Officers dated $5^{\text {th }}$ April, 2019.

Moono, M., Mwinsa, G. M., Mwanabayeke, B., Sikota, E., Mwiinga, C., Sinkala M., Mubanga, C., \& Chakanyika, W. (2019). The implementation of subject specialisation in primary schools: Analysis of its benefits and challenges. International Journal of Multidisciplinary Research and Development, 6(11), 64-72.

Ndawi, O. P. (2002). Showing teacher experience expertise through subject specialisation in the primary schools (STESS). Zimbabwe Journal of Educational Research, 14(3), 272-303. https://doi.org/10.4314/zjer.v14i3.26016

Ndhlovu, F. (2017). Challenges experienced by primary schools in the implementation of subject specialisation in Bubi district primary. International Journal of Multidisciplinary Research and Development, 3(4), 191-195.

Nelson, G. D. \& Landel, C.C. (2007). A collaborative approach for elementary science. Educational Leadership, 64(4), 72-75.

OFSTED (1997). Using Subject Specialists to Promote High Standards at Key Stage 2: An Illustrative Survey. London: OFSTED.

Olakumbi, Akinijide \& Ehindreo. (2012). Primary school teachers' comfortability with generalised teaching in public schools in Osun state, Nigeria. World Journal of Education, 2(1), 145-153. https://doi.org/10.5430/wje.v2n1p145

Pollock K., \& Mindzak M. (2015). Specialist teachers: A review of the literature prepared for the elementary teachers' in the Federation of Ontario. Ontario: The Elementary Teachers' Federation of Ontario.

Prasad R. (2011). Proposing subject specialisation for Fijian Primary Schools, Fiji national university: Fiji Institute of Applied Studies, 14(2).

Roy, J. (2016). The benefits of Teacher Specialisation in the Upper Elementary Classroom. Linkedin Pulse, 18th January. Retrieved from www.linkedin.com/pulse/benefits-teacherspecialisation-upper-elementary-classroom-jesse-ray

Samukange, W. (2015). Subject specialisation at primary school. A new development in the Zimbabwean education system. Global Journal of Advanced Research, 2(5), 845-854.

SAQMEC (2018). The Southern and Eastern Africa Consortium for Monitoring Educational quality: Reading and Math achievement levels and scores. Lusaka: ECZ.

Scwartz, R. S., \& Gess-Newsome, J. (2008). Elementary science specialty: a pilot study of current models and a call for participation in the research. Science Educator, 17(2), 19-30.

Shulman L., \& Shulman J. (2004). How and what teachers learn: A shifting perspective. Journal of Curriculum 
Studies, 36(2), 257-271. https://doi.org/10.1080/0022027032000148298

Shulman, L. S. (1986a). Paradigms and research programs in the study of teaching: A contemporary perspective. In Wittrock, M. C. (Ed.), Handbook of research on teaching (3rd ed., pp. 3-36). New York: McMillan Publishing Company.

Shulman, L. S. (1986b). Those who understand: Knowledge growth in teaching. Educational Researcher, 15(2), 4-14. https://doi.org/10.3102/0013189X015002004

Shulman, L. S. (1987). Knowledge and teaching: Foundations of the new reforms. Harvard Educational Review, 57(1), 1-22. https://doi.org/10.17763/haer.57.1.j463w79r56455411

Thomas, M. A. M., Serenje-Chipindi, J., \& Chipindi, F. M. (2020). Comparing course syllabi from A to Z: Examining the contexts, content, and concerns for social foundations of education in Australia and Zambia. In A. E. Mazawi \& M. Stack (Eds.), Course Syllabi in Faculties of Education across the World: Bodies of Knowledge and their Discontents (pp 38-50). Sydney: Bloomsbury, ISBN 978-1-3500-9425-3 (hardback) 978-1-3500-9427-7 (online).

Thornton, M. (1998). Subject Specialists-Primary Schools. (Universities Council for the education of teachers, Occasional papers, 10). Retrieved from http://www.ucet.ac.uk/op10html

Winther-Jensen, T. (2001). Changing cultures and schools in Denmark. In J. Cairns, D. Lawton and R. Gardner (Eds.), World Yearbook of Education 2001: Values, culture and education (pp. 178-189). London: Kogan Page Limited pp. 178-189.

\section{Copyrights}

Copyright for this article is retained by the author(s), with first publication rights granted to the journal.

This is an open-access article distributed under the terms and conditions of the Creative Commons Attribution license (http://creativecommons.org/licenses/by/4.0/). 